\title{
A multimedia HyperCard stack for the computerized investigation of chromesthetic associations
}

\author{
JOSHUA A. VAUGHN and TERRI L. BONEBRIGHT \\ DePauw University, Greencastle, Indiana
}

\begin{abstract}
Most researchers investigating the perceptual similarities between visual and auditory stimuli have used different presentation methods for the two stimulus modalities. In contrast, a HyperCard stack has been developed which provides an integrated, fully computerized method for examining the chromesthetic associations of auditory stimuli (both pure tones and musical excerpts) and visual stimuli (48 colored rectangles). Advantages of the stack include control over the presentation of stimuli, control for order effects, a user-friendly interface, limited opportunities for demand characteristics or procedural errors, and simplified data compilation. The multimedia capabilities of HyperCard make it an excellent platform for cross-modal research.
\end{abstract}

Researchers investigating the perceptual similarities between visual and auditory stimuli have focused on two areas: assessment of the possible equivalence of vision and audition for understanding graphs and numeric distributions, and measurement of chromesthetic responses to pure tones and musical passages. In most of these studies, different presentation methods have been used for the two stimulus modalities.

In the area of graphs and distributions, Flowers and Hauer $(1992,1993,1995)$ performed several studies to compare the perceptual structure of visual and auditory representations of statistical distributions and time series functions. The stimuli in these studies were data points depicted by graphs printed on cards or by changes in frequency of computer-generated tones. In a related study, Turnage, Bonebright, Buhman, and Flowers (1996) used overhead transparencies to present the visual versions of waveforms, whereas the tones representing the waveforms were presented by a computer.

In examinations of chromesthetic associations, researchers have also tended to use separate presentation formats. Subjects in Marks's (1974) experiment listened to pure tones generated by an oscillator and made a selection from a set of cards that varied in brightness from black to white. Block (1983) presented subjects with tones played on a pipe organ and asked them to select a corresponding hue from a color wheel. Polzella and his colleagues played recordings of classical pieces and simply asked subjects which primary hue was most vividly evoked by the music without presenting any visual stim-

The HyperCard stack described in this article is available on the World-Wide Web at http://www.psych.uiuc.edu/ jvaughn, or by anonymous ftp at the MacPsych archive at ftp.stolaf.edu/pub/macpsych. Correspondence should be addressed to J. A. Vaughn, who is now at the Department of Psychology, 603 East Daniel Street, University of Illinois, Champaign. IL 61820 (e-mail: jvaughn@s.psych.uiuc.edu). uli (Polzella \& Biers, 1987; Polzella \& Kuna, 1981; Polzella, Kuna, Biers, \& DaPolito, 1982). Finally, Sebba (1991) asked her subjects to make a color painting of the image that a musical selection evoked in them.

In contrast to the previously mentioned studies, a study by Marks (1987) was designed with a consistent presentation format for the examination of the perception of temporal patterns in three modalities presented by a Commodore 64 computer. However, today's computers and software packages have advanced multimedia capabilities which allow the presentation of more sophisticated stimuli than those used by Marks, such as a wide spectrum of colors and digitally sampled tones and music. Unfortunately, the potential of computerized control in research involving music and color has been widely ignored (Kendall \& Carterette, 1992). Therefore, the purpose of the present project was to develop a fully computerized procedure for examining the chromesthetic associations between auditory and visual stimuli.

A HyperCard stack was designed that controls the presentation of auditory stimuli (both pure tones and musical excerpts) and records subjects' corresponding selections from a set of visual stimuli (a grid of 48 colors) and from a set of descriptions of the intensity of their chromesthetic experience. In addition, the stack simplifies data analysis by saving data in a form that can be read by a spreadsheet or statistics program. Although the stack will be described in this article as it was set up for these specific stimuli, it can be modified relatively easily to incorporate different sets of auditory and visual stimuli.

\section{THE HYPERCARD STACK}

\section{Apparatus and Software}

A Power Macintosh 7100/80 computer equipped with an Apple Multiple Scan 15-in. Display, CD-ROM drive, AKG K240 stereo headphones, and Version 2.2 of Hyper- 
Card (1993) was used to design and run the stack. SoundEdit 2.0.3 (1990), CD-ROM Toolkit 1.5.8 (1995), and Canary Bioacoustics Research Program 1.2 (1995) were also used in the design process.

\section{Auditory Stimuli}

The stack presents three sets of auditory stimuli: two sets of 36 pure tones followed by one set of 12 musical excerpts. The 36 pure tones were produced with the tone generator function of SoundEdit and were saved as resource files that could be played from within the HyperCard stack. The stimuli consist of three octaves of the 12-tone chromatic scale beginning with $\mathrm{C}$ at $262 \mathrm{~Hz}$ and ending with B at $1976 \mathrm{~Hz}$. Each of the 36 tones has a 2-sec duration.

The musical stimuli are the same 12 excerpts from Handel's Concerti Grossi, Op. 6 used by Polzella and Kuna (1981) and Polzella et al. (1982). The excerpts used in Polzella's studies were identified by referring to the musical score (Handel, 1739/1968), and they were sampled from a CD recording (Handel, 1981/1983) at a monaural sampling rate of $11.025 \mathrm{kHz}$ using the com- puter's CD-ROM drive and the CD-ROM Toolkit software package. The sampled sound files were edited to $90-\mathrm{sec}$ sections using Canary and were converted to HyperCard resource files using SoundEdit.

\section{Visual Stimuli}

A screen shot of the main card of the HyperCard stack is shown in Figure 1. The color response options for each auditory stimulus are presented on the computer screen in a $7 \times 7$ grid of rectangular buttons. These colored buttons are outlined in black and presented on a white background to minimize the effects of visual contrast (Marks, 1974,1978 ). In the center of the grid is the play button, a white button labeled with a black music icon, which allows subjects to control the presentation of the auditory stimuli.

The 48 color responses vary on two dimensions: hue and lightness. The 12 hues were those found at points $30^{\circ}$ apart on the Power Macintosh computer's color wheel, which is based on the primary colors of red, green, and blue. Thus, there are three ancillary hues between each pair of primary hues: orange, yellow, and yellow/green
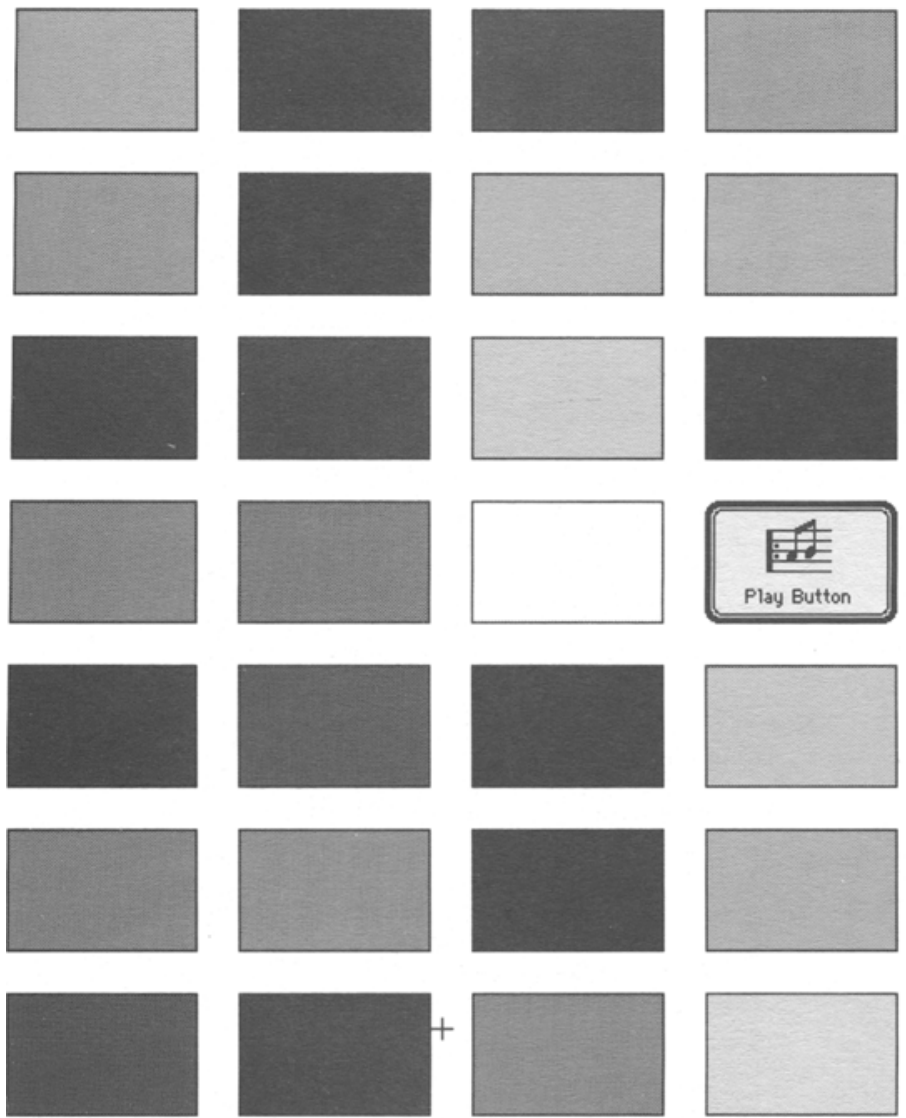
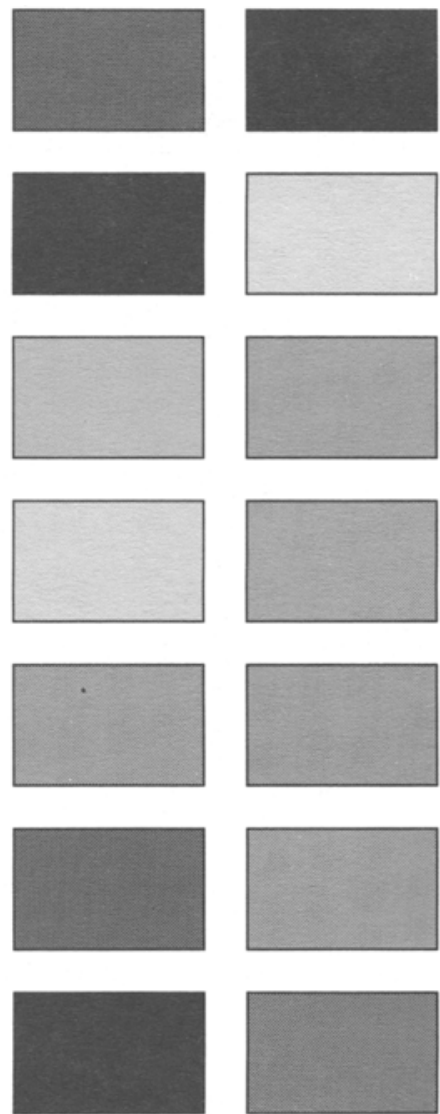
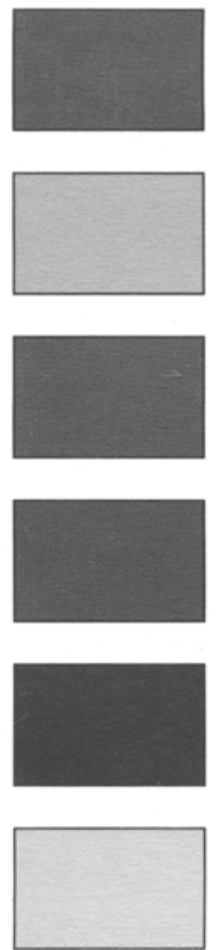

Brilliant color experience

Sounded like color, didn't see

Made me feel like color does

No color experience at all

Figure 1. A screen shot of the main card of the HyperCard stack. 
lie between red and green; green/cyan, cyan, and blue/ cyan lie between green and blue; and violet, magenta, and red/magenta lie between blue and red. Each hue is presented at four levels of lightness: (1) pale, which consists of $40 \%$ light of the specific hue and $60 \%$ white light; (2) light, which consists of $70 \%$ light of the specific hue and $30 \%$ white light; (3) medium, the fully-saturated specific hue at full intensity; and (4) dark, the specific hue at $70 \%$ intensity.

The color experience scale, originally developed by Lehman (1972) to measure the subjective intensity of chromesthetic responses to music, is used to determine the strength of the subject's color experience of each auditory stimulus. The scale is presented at the bottom of the screen on four white buttons, each with an abbreviated phrase representing a level of color experience intensity.

\section{Procedure}

Instructions and demographics questions are presented visually on cards at the beginning of the stack. Dialog boxes announce the beginning of each set of auditory stimuli, which the subjects listen to through the headphones. Subjects start each trial by clicking on the play button, which triggers the presentation of an auditory stimulus. After each stimulus is played, subjects use the mouse to select a color response and a color experience scale response from the choices presented on the computer screen as described above.

\section{Data Collection}

A hidden field in the stack is used to store the data from each trial. A script in the play button sends information about each auditory stimulus into this field. Similarly, scripts in each color button and color response button send the corresponding information about that response into the field. After each subject completes the session, the field contains all the necessary data, which can be printed or saved for later analysis.

\section{CONCLUSION}

To the authors' knowledge, this is the first fully computerized procedure for the examination of chromesthetic associations. Using a multimedia HyperCard stack to control the presentation of both auditory and visual stimuli is a more integrated methodology than using different methods of presentation for the two stimulus modalities. The authors have completed a study of the chromesthetic associations of 45 undergraduate students using the HyperCard stack. In this study, we controlled for order effects by using two versions of the stack, with different random orders of the auditory stimuli and different random patterns of the color stimuli. It would also be possible to randomize the order of the auditory stimuli for each subject. The completely mouse-driven interface and the play button feature, which allowed the subjects to control the pace of the study themselves, made the HyperCard stack user-friendly. None of the students in the study had any noticeable difficulties in using the computer. The stack also simplified the study from the perspective of the experimenters, allowing few opportunities for demand characteristics or errors in the procedure.

Because the multimedia capabilities of HyperCard allow the design of stacks to control the presentation of complex auditory and visual stimuli, HyperCard is an excellent platform for cross-modal research. A similar HyperCard stack could be designed for assessing the possible equivalence of vision and audition for understanding graphs and numeric distributions. In addition to presenting graphs in each modality separately, such a stack could also present a graph in both modalities simultaneously to see whether an auditory signal would enhance the comprehension of a visual graph. The second author is in the process of using a HyperCard stack to investigate facial and vocal attractiveness. The stack will present digitized photographs and vocal samples of various people and ask subjects to rate each person on several personality variables. The stack will also include a card which asks subjects to match vocal samples to photographs.

\section{REFERENCES}

BLOCK, L. (1983). Comparative tone-color responses of college music majors with absolute pitch and good relative pitch. Psychology of Music, 11, 59-66.

Canary Bioacoustics Research Program i.2 [Computer software]. (1995). Ithaca, NY: Cornell University, Laboratory of Ornithology. CD-ROM ToOLKIT I.5.8 [Computer software]. (1995). Menlo Park, CA: FWB Software.

Flowers, J. H., \& HAUER, T. A. (1992). The ear's versus the eye's potential to assess characteristics of numeric data: Are we too visuocentric? Behavior Research Methods, Instruments, \& Computers, 24, 258-264.

Flowers, J. H., \& HaUer, T. A. (1993). "Sound" alternatives to visua! graphics for exploratory data analysis. Behavior Research Methods, Instruments, \& Computers, 25, 242-249.

Flowers, J. H., \& Hauer, T. A. (1995). Musical versus visual graphs: Cross-modal equivalence in perception of time series data. Human Factors, 37, 553-569.

HANDEL, G. F. (1968). Twelve concerti grossi, opus 6 (Vols. 1-2). New York: Kalmus. (Original work composed 1739)

HANDEL, G. F. (1983). Twelve concerti grossi, opus 6 [Recorded by Academy of St. Martin-in-the-Fields (Iona Brown, Director), 3-CD set]. Holland: Phillips. (1981)

HyPERCARD 2.2 [Computer software]. (1993). Cupertino, CA: Apple Computer.

Kendal., R. A., \& Carterette, E. C. (1992). Convergent methods in psychomusical research based on integrated, interactive computer control. Behavior Research Methods, Instruments, \& Computers, 24, 116-131.

LEHMAN, R. S. (1972). A multivariate model of synesthesia. Multivariate Behavioral Research, 7, 403-439.

MARKS, L. E. (1974). On associations of light and sound: The mediation of brightness, pitch, and loudness. American Journal of Psychology, 87, 173-188.

MARKS, L. E. (1978). The unity of the senses: Interrelations among the modalities. New York: Academic Press.

MARKS, L. E. (1987). On cross-modal similarity: Perceiving temporal patterns by hearing, touch, and vision. Perception \& Psychophysics. 42, 250-256.

Polzella, D. J.. \& Biers, D. W. (1987). Chromesthetic responses to music: Replication and extension. Perceptual \& Motor Skills, 65, 439-443. 
Polzella, D. J., \& Kuna, A. M. (1981). Chromesthetic responses to the music of G. F. Handel. In E. Klinger (Ed.), Imagery: Vol. 2. Concepts, results, and applications (pp. 165-173). New York: Plenum. Polzella, D. J., Kuna, A. M., Biers, D. W., \& DaPolito, F. (1982) Hemispheric asymmetry in musically-induced color imagery. Psychomusicology, 2, 64-71.

SEBBA, R. (1991). Structural correspondence between music and color. Color Research \& Application, 16, 81-88.

SoundEDIT 2.0.3 [Computer software]. (1990). Emeryville, CA: Farallon Computing.
Turnage, K. D., Bonebright, T. L., Buhman, D. C., \& Flowers, J. H (1996). The effects of task demands on the equivalence of visual and auditory representations of periodic numerical data. Behavior $R e-$ search Methods, Instruments, \& Computers, 28, 270-274.

(Manuscript received November 14, 1996; revision accepted for publication February 10, 1997.) 